\title{
Utilization of spatial interpolation technique to compare metal accumulation pattern by lichens in plain and mountainous regions of North Central India
}

Rajesh Bajpai ( $\square$ bajpaienviro@gmail.com )

CSIR-National Botanical Research Institute

Vertika Shukla

BBA University Lucknow

C P Singh

SAC ISRO Ahmedabad

Ashwani Raju

BHU Vransi

D K Upreti

NBRI Lucknow

\section{Research Article}

Keywords: Lichens, topography, GIS mapping, interpolation technique, biomonitoring

Posted Date: June 9th, 2021

DOI: https://doi.org/10.21203/rs.3.rs-342794/v1

License: (a) (1) This work is licensed under a Creative Commons Attribution 4.0 International License.

Read Full License 
Utilization of spatial interpolation technique to compare metal accumulation pattern by lichens in plain and mountainous regions of North Central India

$4 \quad{ }^{1}$ Lichenology laboratory, Plant Diversity systematics and Herbarium Division, CSIR-National Botanical Research

5 Institute, Lucknow, India

$6{ }^{2}$ Department of Geology, Babasaheb Bhimrao Ambedkar (Central) University, Vidya Vihar, Raebareli Road,

7 Lucknow, India

$8 \quad{ }^{3}$ Remote Sensing \& GIS Lab., Centre of Advanced Study in Geology, Banaras Hindu University, Varanasi, Uttar

9 Pradesh, India

$10 \quad{ }^{4} \mathrm{AED} / / \mathrm{BPSG} / \mathrm{EPSA}$, Space Applications Centre-ISRO, Ahmedabad, India

11

12

\section{$13 \quad{ }^{\$}$ Corresponding Author}

14

24 \# Authors contributed equally 


\section{Utilization of spatial interpolation technique to compare metal accumulation pattern by lichens in plain and} mountainous regions of North Central India

\author{
Rajesh Bajpai ${ }^{1 \# \$}$, Vertika Shukla ${ }^{2 \#}$, Ashwani Raju ${ }^{3}$, Chandra Prakash Singh $^{4}$ and Dalip Kumar Upreti ${ }^{1}$ \\ ${ }^{1}$ Lichenology laboratory, Plant Diversity systematics and Herbarium Division, CSIR-National Botanical Research \\ Institute, Lucknow, India \\ ${ }^{2}$ Department of Geology, Babasaheb Bhimrao Ambedkar (Central) University, Vidya Vihar, Raebareli Road, \\ Lucknow, India \\ ${ }^{3}$ Remote Sensing \& GIS Lab., Centre of Advanced Study in Geology, Banaras Hindu University, Varanasi, Uttar \\ Pradesh, India
}

${ }^{4}$ AED//BPSG/EPSA, Space Applications Centre-ISRO, Ahmedabad, India

\section{Abstract}

Based on the physicochemical characteristics, metals emitted from the source (both natural and anthropogenic) contributes towards spatial continuity at regional scale. Apart from intrinsic properties of metals, meteorological conditions and topography of the region is also known to contribute towards the spatial continuity. In the present study comparative spatial assessment of twelve metals in lichen Phaeophyscia hispidula collected from mountains and plains of north western India was carried out with the help of indicator kriging method. In plains and mountains the total metal concentration varies between $25.38-429.24 \mu g^{-1}$ and $22.77-506.95 \mu g g^{-1} \mathrm{dry}$ weight respectively. Geospatial mapping provided insight into the spatial behavior of different metals in plain and mountain regions. In plains, $\mathrm{Cr}, \mathrm{Cd}, \mathrm{Cu}$ and $\mathrm{Pb}$ had higher concentration having higher coverage area, while metals like $\mathrm{Cd}$ and $\mathrm{Hg}$ had highest localized distribution indicating point sources. Observations indicated that apart from local sources, meteorological conditions specially wind direction also plays important role in spatial behavior of the metals, which has been verified by the bioaccumulation pattern of metals in lichen samples from mountainous region. Among which three mountainous states of North Western India, Uttarakhand has higher concentration of metals which may be attributed to the wind direction together with local anthropogenic sources.

Key Words: Lichens; topography; GIS mapping, interpolation technique, biomonitoring

\section{Introduction}

Heavy metals pose serious threat to the ecosystem due to its bioaccumulation and biomagnification properties. Both anthropogenic and geogenic (lithogenic) sources result in environmental contamination at local/regional/global scale. The diversity and distribution of various metals is known to be mainly influenced by emission source and climatic condition (Serelis et al. 2010). Quantification of metals merely provides the variation in the metal concentration at different locations. In order to understand the dispersal of metals and its ecotoxicological potential, spatial behaviour of metal requires to be investigated. Spatial interpolation technique visualizes the continuity and variability of sample data by creating continuous prediction surface onto a geographical space. As an effective tool of Geographical Information System (GIS), interpolation techniques compile and analyze 
widespread data for precise regional representation of the variables from multiple sources as well as locales. The statistical interpolation methods illustrate spatial prediction at unknown points and can be used for diverse mapping applications for assessment of 'spatial risk' in health science, geochemistry, pollution modeling or climatic phenomenon at regional as well as global scale (Lam 1983; Watson 1992).

Spatial prediction of the above phenomenon's can be approximated by a function depending on the spatial heterogeneity and location of irregularly distributed sample points in geographical space (Mitas and Mitasova 1999). Kriging, one of the widely accepted interpolation techniques, has the advantage of considering the spatial structure of the variable, i.e., known spatially correlated distance or direction biases in the data points (Cattle et al. 2002; Raju et al. 2019). In recent years, a non-parametric approach based geostatistical kriging or cokriging estimator has been widely experienced to predict the probabilistic evidence of an unsampled point $Z[x, y]$ from unconditional data (Juang and Lee 2000; Passarella et al. 2002; Goovaerts et al. 2005, Adhikary et al. 2011).

The use of lichens in estimating the quality of the air, from different parts of the world are available and well studied more than four decades and published $>2000$ account on the lichen and environmental studies (Garty 2001, Shukla et al. 2014; Liu et al. 2016). However, the lichen biomonitoring data has been well utilized to predict the air quality of the area of interest, yet very few studies have been conducted in the country to investigate the regional pattern of metal pollution and its dispersal (Bajpai et al. 2010, 2014).

In the present study effort has been made to utilize spatial interpolation technique to compare the metal accumulation pattern at regional scale in plain and mountainous regions of North western India using lichen biomonitoring data to investigate the spatial behavior of metals studied and identify the pollution in disturbed areas and for framing regulatory policies.

\section{Materials and methods}

Study area and sample collection: The samples of a common foliose lichen Phaeophyscia hispidula (Ach.) Essl, was collected from different parts of the north central India by the authors RB and VS during 2016-2019 (Fig 1). The voucher (duplicate) specimens are deposited in CSIR-National Botanical Research Institute, Herbarium (LWG). At least three lichen samples with 3 replicate each $(n=9)$ from each site was used for the analysis.

Elemental analysis: The oven-dried $\left(70^{\circ} \mathrm{C}\right)$ lichen samples were grounded to fine powder and digested $(0.5 \mathrm{~g})$ in $\mathrm{HNO}_{3}: \mathrm{H}_{2} \mathrm{O}_{2}(3: 1 \mathrm{v} / \mathrm{v})$. After digestion the volume was made to $5 \mathrm{ml}$ by Milli Q water. Prior to analysis the samples were diluted 10 times and the concentration of elements ( $\mathrm{Fe}, \mathrm{Zn}, \mathrm{Co}, \mathrm{Ni}, \mathrm{Cu}, \mathrm{Se}, \mathrm{Mn}, \mathrm{Mo}, \mathrm{Cd}, \mathrm{Hg}, \mathrm{Cr}$ and $\mathrm{Pb}$ ) was analysed using an Inductively Coupled Plasma Mass Spectrometer (ICP-MS, Agilent $7500 \mathrm{CE}$ ) following method by Dwivedi et al. (2010), internal standardization of all the samples was done by adding Rhodium (4 $\left.\mathrm{g} \mathrm{l}^{-1}\right)$.

The standard reference materials of metals/metalloids (E-Merck, Germany) were used for the calibration and quality assurance for each analytical batch. Analytical data quality of metals/metalloids was ensured with repeated analysis $(n=3)$ of quality control samples, and the results were found within $( \pm 2.82)$ the certified values. Recovery of $\mathrm{Fe}, \mathrm{Zn}, \mathrm{Mn}, \mathrm{Cu}, \mathrm{Co}, \mathrm{Se}, \mathrm{Cr}, \mathrm{Pb}$ and $\mathrm{As}$ from the samples were found to be more than $98 \%$, as 
determined by spiking of samples with a known amount of elements. The detection limit for each element was $1 \mu^{-}$ 1.

97 Kriging for spatial interpolation: The spatial distribution of the random variable in space is the function of structural 98 component showing the spatial trend of the variables $\left[m\left(x_{i}\right)\right]$, stationary regionalized component defining the local 99 variation between the variable in space $\left[\varepsilon\left(x_{i}\right)\right]$, and random noise independent on location $\left(\varepsilon^{\prime}\right)$ within the framework of a linear model. Spatial interpolation considers spatial autocorrelation between the random variables $\left[Z\left(x_{i}\right) ; i \in\right.$ $\{1 \ldots n\}]$ to transform a regional database (elemental concentration in lichen Phaeophyscia hispidula) on to a smooth continuous surface. Spatial autocorrelation specifies the spatial dependency between the random variables and estimated through semivariogram (Berke 2004). Semivariogram defined as the half variance of the average square difference between points $\left[Z\left(x_{i}\right)\right]$ and $\left[Z\left(x_{i}\right)+h\right]$ separated at lag distance $(h)$ and represented by Eq. 1 where, $\gamma(h)$ is semivariance, $Z$ is the known variable at the location $\left(x_{i}\right), n$ is the number of pairs of sample point $Z\left(x_{i}\right)$ and $h$ is the lag width or distance between the pair of points $\left(x_{i}\right)$ and $\left(x_{i}+h\right)$ (Matheron 1963).

107
parameters i.e. nugget $\left(\mathrm{C}_{0}\right)$, sill $\left(\mathrm{C}_{0}+\mathrm{C}_{1}\right)$ and range $\left(\mathrm{C}_{2}\right)$ using weighted least square technique. The best fitted semivariogram model allows predicting the variables $\left(Z^{\prime}\right)$ at unknown locales $\left(x_{o}\right)$ (Hohn 1999).

\section{Indicator Kriging}

Indicator kriging assumes a model where regionalized spatial autocorrelation between the random variable is a function of binary variable. The binary values are the indicator codes $\left[I\left(x_{i}\right)=0\right.$ or 1$]$ transformed from the random variables $\left[Z\left(x_{i}\right) ; i \in\{1 \ldots n\}\right]$ through the use of desirable threshold $\left(Z_{t h}\right)$ for continuous data (Hohn 1999). The indicator codes are estimates as 1 if $Z\left(x_{i}\right) \geq Z_{t h}$, otherwise considered as 0 . Spatial autocorrelation between the indicator codes (binary variables) is calculated using semivariogram function (Eq. 2) and best fit model codes and nugget $\left(\varepsilon^{\prime \prime}\right)$ measure the variance of non-spatially autocorrelated noise of indicator codes.

$$
\gamma_{i}(h)=\frac{1}{2 n(h)} \sum_{i=1}^{n(h)}\left\{I\left(x_{i} ; z_{t h}\right)-I\left(x_{i}+h ; z_{t h}\right)\right\}^{2} \#
$$

The derived value of semivariance $\left[\gamma_{i}(h)\right]$ of the indicator codes and Lagrange multiplier $\left(L_{m}\right)$ is used to obtain weighted coefficient $\left(\lambda_{i}\right)$ (Eq. 3) and spatial prediction $\left(I^{\prime}\right)$ at an unknown point $\left(x_{0}\right)$ is calculated using

124 indicator kriging estimator using Eq. 4. As the value of indicator codes $I\left(x_{i}\right)$ are 0 or 1 , the predicted probability 125 variable also range in class 0 to 1. 


$$
I^{\prime}\left(x_{0} ; z_{t h}\right)=\sum_{i=1}^{n} \lambda_{i} I\left(x_{0} ; z_{t h}\right)
$$

The suitability of exponential semivariogram models for prediction of indicator values are validated using Cross validation technique.

\section{Results and Discussion}

Twelve metals (Cr, Mn, Fe, $\mathrm{Co}, \mathrm{Ni}, \mathrm{Cu}, \mathrm{Zn}, \mathrm{Se}, \mathrm{Mo}, \mathrm{Cd}, \mathrm{Pb}$ and $\mathrm{Hg}$ ) of geogenic as well as anthropogenic 132 origin were analyzed in lichen, Phaeophyscia hispidula collected from different locations of northern plains (Uttar 133 Pradesh, Madhya Pradesh, some parts of Chhattisgarh) and mountainous states (Jammu \& Kashmir, Himachal 134 Pradesh and Uttarakhand) of India. Result revealed substantial variation in the concentration of different metals in 135 the two regions; in plains and mountains; the total metal concentration varied between $25.38-429.24 \mu \mathrm{gg}^{-1}$ and $13622.77-506.95{\mu \mathrm{gg}^{-1}}^{-1}$ ry weight respectively (Table 1). Among all the localities highest concentration was observed 137 for iron $\left(345.6 \mu \mathrm{gg}^{-1}\right)$ followed by manganese $\left(341 \mu \mathrm{gg}^{-1}\right)$ and zinc $\left(179.66 \mu \mathrm{gg}^{-1}\right.$ dry weight) in lichen samples from 138 Uttarakhand. Results shows that in plains metals are having wider distribution, while in mountains among the three states considered, Uttarakhand and Himachal Pradesh also has substantial presence of anthropogenic metals like Mercury (1.57 $\mu \mathrm{gg}^{-1}$ dry weight), Lead (228.08 $\mu \mathrm{gg}^{-1}$ dry weight) and Chromium (75.46 $\mu \mathrm{gg}^{-1}$ dry weight).

Among the various metals analyzed in lichen samples, from both plains and mountainous regions of India, showed variation in concentration of metals which may be due to local emissions or long range transport. The concentration of various metals analyzed in lichen Phaeophyscia hispidula samples from both plains and mountainous regions of India have used as point data (random variable) to generate a regional database for spatial interpolation. The concentration values of all twelve metals have transformed into indicator codes and spatial autocorrelation between them have been estimated from empirical semivariogram. The exponential semivariogram model has found best fitted to the experimental semivariogram of indicator codes and optimized values of nugget, sill and range of influence for each metal concentration has noted (Table 2). The semivariogram models for all metal concentration has explained and illustrated with an example of Cd.

The best fit exponential semivariogram model for indicator codes of $\mathrm{Cd}$, shown as an example, indicates a nugget variance, $\mathrm{C}_{0}$ of 0.039 with the sill, $\mathrm{C}_{0}+\mathrm{C}_{1}$ (maximum elemental concentration in Lichen) ${ }^{2}$ and the range of 152 influence, $\mathrm{C}_{2}$ as 20.72 and $27.75 \mathrm{~km}$, respectively. Semivariogram parameters indicated that indicator codes of $\mathrm{Cd}$ 153 have high spatial autocorrelation within the range of $27.75 \mathrm{~km}$ radius. The model indicated that the nugget variance 154 is quite low (0.039) as compared to its corresponding maximum value of semivariance (sill) i.e. 2.072 (Table 2). A 155 small value of nugget indicates the low non-spatially auto correlated variance of indicator codes. The quality of semivariogram model is explained by the semivariance percentage calculated using Eq. 5 which indicated that 
$\sim 95.89 \%$ of the semivariance of the indicator codes is modeled by the semivariogram over a range of $27.75 \mathrm{~km}$ radius.

$$
\text { Maximum Semivariance } \%=\frac{\left[\gamma_{i}(h)\right]-\left[\left(\varepsilon^{\prime \prime} x_{i}\right)\right]}{\left[\gamma_{i}(h)\right]} \times 100 \#
$$

The resultant semivariogram model and corresponding optimized semivariogram parameters for all elements are cross-validated. The cross-validation result of $\mathrm{Cd}$ concentration for an example is shown in Fig 2 . The semivariogram models and cross validation for all twelve metal concentrations have been interpreted and explained in a similar way as $\mathrm{Cd}$ (Table 2 and Fig.3). Mean error and average standard error for exponential semivariogram models of all elemental concentration are within a range of 0.0042-0.067 and 0.44-0.51, respectively. Finally, predicted probability distribution maps of the corresponding element are later generated from indicator kriging estimator using Eq. 4. The predicted probability maps show a variable degree of all twelve metal concentrations at a scale of 0 to 1 both plain and mountainous regions of India.

The predicted probability maps of individual metals showed that spatial continuity of metals is more in plains while mountainous sites showed local hot spots, only mercury and cadmium showed highest spatial continuity in mountainous region (Fig 4 and Fig 5). Mercury is known to be emitted to the atmosphere from both natural and anthropogenic sources. The coal combustion, waste incineration, mining, refining and manufacturing and chlorinealkali production are the major sources of $\mathrm{Hg}$ in the atmosphere. The human activities emit both elemental $\mathrm{Hg}$ with 173 long life in the atmosphere and reactive gaseous mercury (RGM) and particulate $\mathrm{Hg}$, which has short resident life in 174 the air and are deposited near the emission source. It has been observed that natural sources are believed to be rich in elemental mercury (Li et al. 2009; Munteanu and Munteanu 2007). Spatial continuity of mercury shows wider distribution of mercury, indicating existence of elemental $\mathrm{Hg}$. Since mercury sources are scanty in the mountains and shows long range transport in the area, yet the conclusion requires extensive monitoring of $\mathrm{Hg}$ in near future.

High spatial continuity of cadmium may be attributed to heavy tourist activity in mountain region due to location of pilgrimage centers in the mountains of north western India. Cadmium is released into the atmosphere by wear and tear of motorcar tires. Both anthropogenic and geogenic sources result in the emission of metals to the environment. Anthropogenic sources of metals are mostly related to vehicular activity as lubricating oil often contains metals like $\mathrm{Cd}, \mathrm{Cu}$, and $\mathrm{Zn}$. Automobile tires and brake pads are potential source of $\mathrm{Zn}$, while car metal plating in welded plates and in tires emit Ni to the environment (Shukla and Upreti 2007; Bajpai et al. 2004). Cd and $\mathrm{Zn}$ are very mobile and highly bioavailable metals which may be the main factor controlling its bioaccumulation in plants including lichens. Geogenic sources mainly include processes like leaching and weathering of rocks. Metals like Co and Ni known to found in organic matter and clays its mobility increases in acidic condition

The relative variation in rate of dispersion is known to be a controlling factor for the spatial continuity of the metals. It has been observed that metals like $\mathrm{Ni}$ and $\mathrm{V}$ reflect the particulate nature, which results in relative low rate of dispersion, while metals like $\mathrm{Cu}$ and $\mathrm{Cr}$ are dispersed in small particles resulting in higher spatial continuity of the metals, which is in conformity with the present observation. 
Influence of topography and wind direction may well be understood by the variation in the metal concentration in the three hilly states of North western Himalayas. Of the three states, metal concentration is highest in Uttarakhand, as due to westerly winds the state is directly exposed to pollution load of northern India and dominant vehicular activity due to pilgrimage.

The present observations reveals the application of lichen biomonitoring data together with GIS tools to record the variation in the metal concentration and its probable correlation with other abiotic and biotic factors provides valuable information regarding its influence in controlling dispersal of pollutants at regional scale.

\section{Conclusion}

The study shows that metal profile is influenced by both anthropogenic and natural sources. The topography also plays an important role in the spatial distribution of metal in different region therefore, an integrated approach is required to understand the environmental consequence of metal and associated health effects. Though the study has been conducted taking few sites representative from various states but it presents the applicability of lichen biomonitoring data for regional mapping. Interpolation requires point data to be distributed normally in space. The study could be more reliable in future if proceed with a large number of samples data. However, the topographical constrain of mountainous region of northern India allow only limited data to collect. The study demonstrates that geographic information system may be predicting the probable zones of high risk. The study could help in planning sustainable environmental development of the concern region on a long term basis.

\section{Acknowledgements}

Authors are thankful to Prof. S. K. Barik, Director, CSIR-National Botanical Research Institute, Lucknow, for providing laboratory facilities for work. The authors RB and DKU thanks to the Council of Scientific and Industrial Research, New Delhi, for award of Scientist Pool fellowship (8909-A) and Emeritus scientist fellowship

212 (21/1045/18/EMR-II) respectively. This manuscript bears CSIR-NBRI, communication Number CSIR-NBRI213 MS/2020/11/07. The authors declare that they have no conflict of interests.

214 Ethical Approval: This article does not contain any studies with human or animals' participants..

215 Consent to Participate: All authors given his/her consent to participate in the manuscript.

216 Consent to Publish: All authors given his/her consent for publication and authors have no conflicts of interest.

217 Authors Contributions: Author RB collected samples, metal estimation and writing first draft of manuscript, VS also collected samples and assist in metals estimation and AR perform kriging analysis of data. Authors CPS and DKU provide fruitful discussions and comments for improving the manuscript.

Funding: Council of Scientific and Industrial Research, New Delhi

221 Availability of data and materials: The lichen voucher specimen was deposited in the herbarium of the CSIR-

222 National Botanical Research Institute, Lucknow (LWG), India. 


\section{References:}

225

226

227

228

229

230

231

232

233

234

235

236

237

238

239

240

241

242

243

244

245

246

247

248

249

250

251

252

253

254

Adhikary PP, Dash CJ, Bej R, Chandrasekharan H (2011) Indicator and probability kriging methods for delineating $\mathrm{Cu}, \mathrm{Fe}$, and $\mathrm{Mn}$ contamination in groundwater of Najafgarh Block, Delhi, India. Environmental monitoring and assessment 176(1): 663-676.

Bajpai R, Shukla V, Upreti DK, Semwal M (2014) Selection of suitable lichen species for monitoring climatic variability in the Himalaya. Environmental Science and Pollution Research 21: 11380-11394.

Bajpai R, Upreti DK, Mishra SK (2004) Pollution monitoring with the help of lichen transplant technique at some residential sites of Lucknow. Journal of Environmental Biology 25 (2): 191-195.

Bajpai R, Upreti DK, Nayaka S, Kumari B (2010) Biodiversity bioaccumulation and physiological changes in lichens growing in the vicinity of coal based thermal power plant of Raebareli district, north India. Journal of Hazardous Materials 174: 429-436.

Berke O (2004) Exploratory disease mapping: kriging the spatial risk function from regional count data. International Journal of Health Geographics 3: 18, doi.org/10.1186/1476-072X-3-18

Cattle JA, Alex B, Bratney MC, Minasny B (2002) Kriging Method Evaluation for Assessing the Spatial Distribution of Urban Soil Lead Contamination. Journal of Environmental Quality 31: 1576-1588.

Dwivedi S, Triparthi RD, Kumar A, Dave R, Mishra S, Singh R, Sharma D, Rai UN, Charakaborty D, Trivedi PK, Adhikari B, Bag MK, Dhankar OP, Tuli R (2010) Arsenate Exposure Affects Amino Acids, Mineral Nutrient Status and Antioxidants in Rice (Oryza sativa L.) Genotypes. Environmental Science and Technology 44: 9542-9549.

Garty J (2001) Biomonitoring atmospheric heavy metals with lichens: theory and application. Crtital Review in Plant Science 20(4): 309-371.

Goovaerts P, AvRuskin G, Meliker J, Slotnick M, Jacquez G, Nriagu J (2005) Geostatistical modeling of the spatial variability of arsenic in groundwater of southeast Michigan. Water Resources Research 41(7): W07013, doi:10.1029/2004WR003705.

Hohn ME (1999) The semivariogram. In: Geostatistics and petroleum geology. Springer, Dordrecht. https://doi.org/10.1007/978-94-011-4425-4_2

Juang KW, Lee DY (2000) Comparison of three nonparametric kriging methods for delineating heavy metal contaminated soils. Journal of Environmental Quality 29: 197-205.

Lam NS (1983). Spatial interpolation methods: a review. The American Cartographer 10: 129-49.

Li P, Feng XB, Qui GL, Shang LH, Li ZG (2009) Mercury pollution in Asia: A review of the contaminated sites. Journal of Hazardous Materials 168: 591-601. 
Liu HJ, Zhao LC, Fang SB, Liu SW, Hu JS, Wang L, Liu XD, Wu QF (2016) Use of the lichen Xanthoria mandschurica in monitoring atmospheric elemental deposition in the Taihang Mountains, Hebei, China. Scientific Report 6: 23456; doi: 10.1038/srep23456.

Matheron G (1963) "Principles of geostatistics". Economic Geology 58 (8): 12461266. doi:10.2113/gsecongeo.58.8.1246

Mitas L, Mitasova H (1999). Spatial Interpolation. In: Longley P, Goodchild MF, Maguire DJ, Rhind DW (Eds.), Geographical Information Systems: Principles, Techniques, Management and Applications, Wiley.

Munteanu V, Munteanu G (2007) Biomonitoring of mercury pollution: A case study from the Dniester River. Ecological Indicator 7: 489-496

Passarella G, Vurro M, D'agostino V, Giuliano G, Barcelona MJ (2002) A probabilistic methodology to assess the risk of groundwater quality degradation. Environmental monitoring and assessment 79(1): 57-74.

Raju A, Singh A, Srivastava N, Singh S, Jigyasu DK, Singh M (2019). Mapping human health risk by geostatistical method: a case study of mercury in drinking groundwater resource of the central ganga alluvial plain, northern India. Environmental Monitoring and Assessment 191 (Supp. 2): 298, doi: 10.1007/s10661019-7427-y.

Serelis KG, Kafkala IG, Parpodis K, Lazaris S (2010). Anthropogenic and geogenic contamination due to heavy metals in the vast area of Vari, Attica. Bulletin of the Geological Society of Greece 43: 2390-2397.

Shukla V, Upreti DK (2007). Heavy metal accumulation in Phaeophyscia hispidula en route to Badrinath, Uttaranchal, India. Environmental Monitoring and Assessment 131: 365-369

Shukla V, Upreti DK, Bajpai R (2014) Lichen to Biomonitor the Environment (ed.). Springer Publishing Netherland Watson DF (1992) Contouring: a guide to the analysis and display of spatial data. Oxford, Pergamon. 


\section{Legends:}

287 Figure 1: Map showing different localities in North Central India from where lichen samples were collected

288 Figure 2: Exponential semivariogram model best fitted to the experimental semivariogram of indicator values transformed from Cd concentration of lichen Phaeophyscia hispidula. The best fit indicates that nugget variance, $\mathrm{C}_{0}$ is 0.039 ; sill, $\mathrm{C}_{0}+\mathrm{C}_{1}$ is 20.72 (elemental concentration in lichen) ${ }^{2}$; the range of influence, $\mathrm{C}_{2}$ is $27.75 \mathrm{~km}$

Figure 3: Cross validation showing relationship between measured and predicted indicator values of $\mathrm{Cd}$ concentration.

294 Figure 4: Predicted probability maps showing distribution of elemental concentration in lichen, Phaeophyscia hispidula in plains of north central India

296 Figure 5: Predicted probability maps showing distribution of elemental concentration in lichen, Phaeophyscia hispidula in mountains of northern India. 


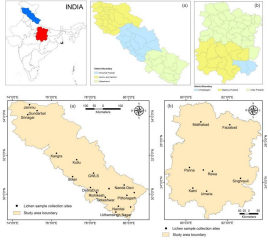




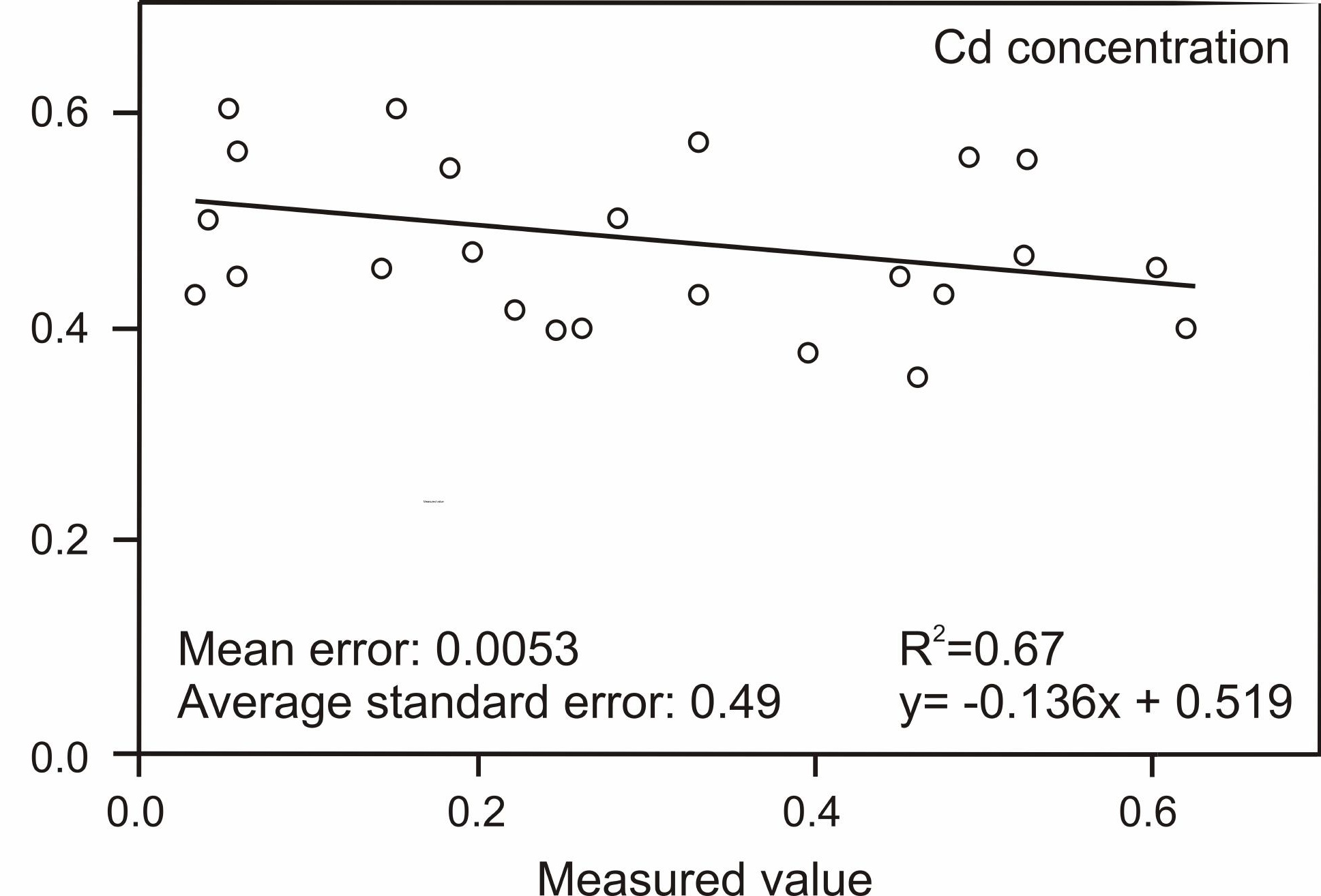




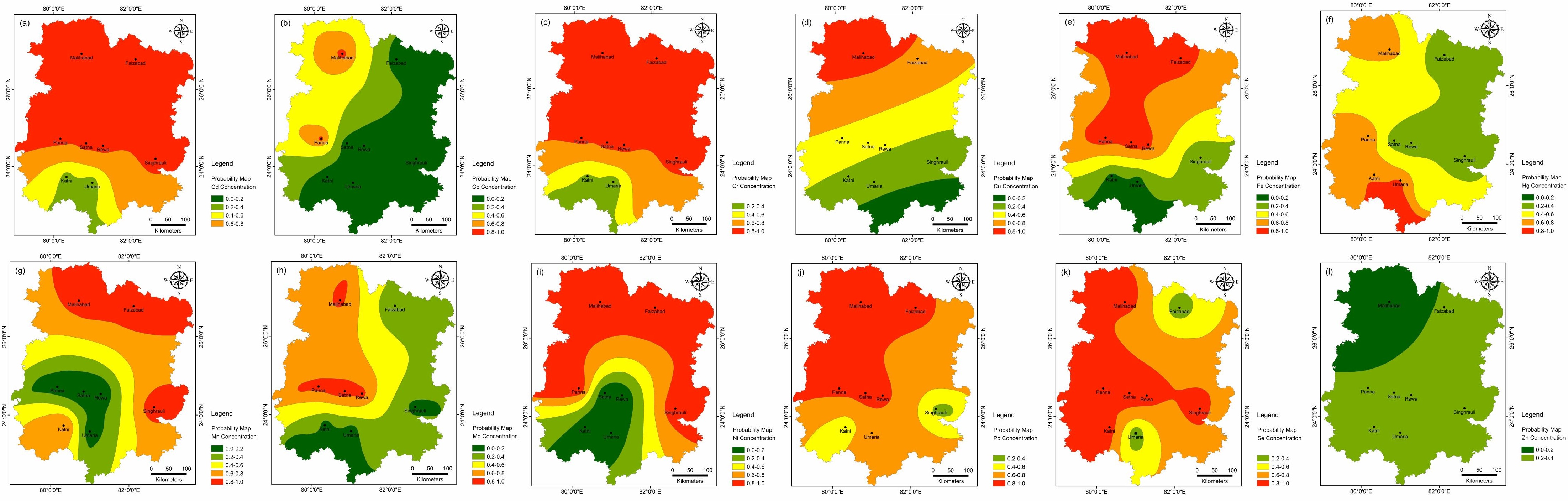




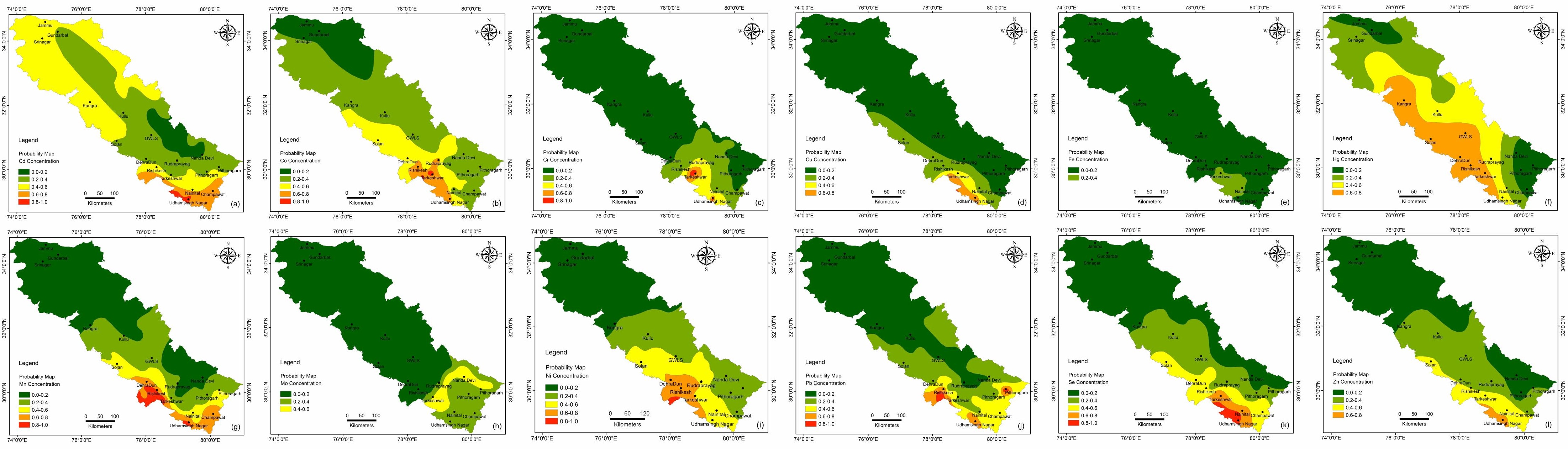

